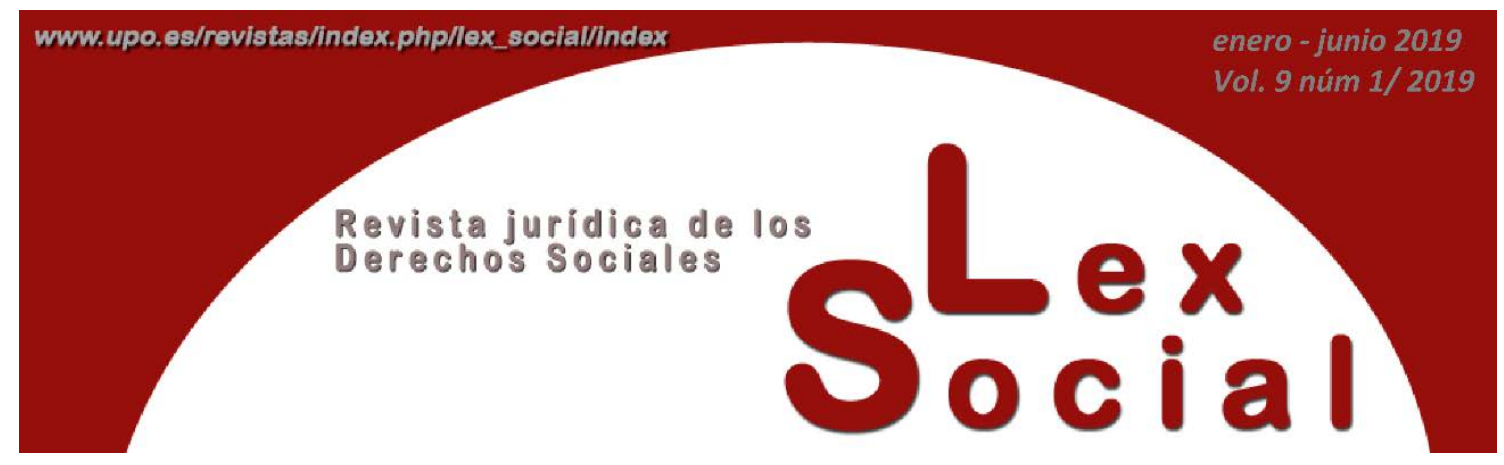

\title{
LA PREVENCIÓN DE RIESGOS LABORALES EN CHILE: ALGUNAS REFLEXIONES SOBRE LA DEUDA DE SEGURIDAD EMPRESARIAL
}

\author{
THE PREVENTION OF LABOR RISKS IN CHILE: SOME \\ REFLECTION ON THE EMPLOYER'S SECURITY OBLIGATION
}

CAYETANO NÚÑ̃EZ GONZÁLEZ

Profesor Titular de Derecho del Trabajo y de la Seguridad Social Instituto Polibienestar - Universitat de València

Artículo recibido el 6 de febrero de 2019

Artículo aceptado el 16 de febrero de 2019

\section{RESUMEN}

La prevención de riesgos laborales es un derecho básico de los trabajadores, por su evidente conexión con el derecho a la vida y a la salud. Su relevancia y complejidad jurídica merecen conocer cómo se regula el deber de seguridad en el ordenamiento jurídico chileno, cuáles son sus características más relevantes y cuál es el alcance de esta obligación empresarial.

Palabras Clave: Recargo, derecho a la vida, derechos Humanos, prevención de riesgos laborales, seguridad y salud en el trabajo, ordenamiento jurídico, contrato de trabajo, deber de seguridad empresarial, artículo 184 Código del Trabajo, Chile. 


\begin{abstract}
The prevention of occupational hazards is a basic right of workers, connected with the right to life. It is important to know how it is regulated in the Chilean law, and analyze its most important characteristics.
\end{abstract}

KEY WoRDs: Increase, right to life, human Rights, prevention, occupational hazards, security and health at work, legal system, labor law, work contract, employer's obligation, Chile.

SUMARIO

1. EL MARCO NORMATIVO CHILENO DE LA PREVENCIÓN DE RIESGOS LABORALES

1.1 El fundamento constitucional

1.2. Las normas internacionales

1.3. Las normas legales y reglamentarias

2. EL ALCANCE DE LA DEUDA DE SEGURIDAD O ESTÁNDAR DE PROTECCIÓN

2.1. La máxima eficacia consiste en evitar los riesgos

2.2. La razonabilidad técnica como estándar de protección

\title{
1. EL MARCO NORMATIVO CHILENO DE LA PREVENCIÓN DE RIESGOS
} LABORALES

El bien jurídico protegido del derecho a la prevención de riesgos laborales es el derecho a la vida, consagrado en Chile en el artículo $19.1^{\circ}$ de la Constitución Política de la República (en adelante, CPR) ${ }^{1}$, en relación con el derecho a la salud regulado en el artículo $19.9^{\circ} \mathrm{CPR}$.

\footnotetext{
${ }^{1}$ Así lo reconoce, la RCS de 26 de abril de 2011, Resolución no 16361 y otras posteriores en toda instancia judicial.
} 
Este derecho fundamental encuentra su principal referencia legal en el artículo 184 del Código del Trabajo (en adelante, CT) ${ }^{2}$. Este precepto concreta la deuda o deber de seguridad, que obliga al empleador "a tomar todas las medidas necesarias para proteger eficazmente la vida y salud de los trabajadores”.

El artículo 184 CT viene acompañado por un amplio despliegue de normas legales y reglamentarias, algunas de naturaleza laboral y otras no, entre las que destaca de un modo relevante la Ley 16744 sobre accidentes de trabajo y enfermedades profesionales de 1968 (en adelante, LAT).

\subsection{EI fundamento constitucional}

Como se advirtió, el derecho a la vida (art. 19. $1^{\circ} \mathrm{CPR}$ ), es el núcleo central del entramado jurídico preventivo chileno. Este derecho, privilegiado, personal, genérico, tiene eficacia en cualquier dimensión del ámbito humano, incluido el productivo, y consiste en el verdadero enclave al que han de ajustarse las demás previsiones normativas ${ }^{3}$.

En efecto, tal y como declaró la OISS en Santiago de Chile, "el derecho a la vida, a la integridad física, a la salud y a la seguridad social es consustancial a la prevención de riesgos laborales, y su protección y promoción determinan un objetivo de primer orden para los Gobiernos, los Interlocutores Sociales y la sociedad en su conjunto”4.

Como derecho fundamental, debe la normativa infra constitucional ajustarse a su contenido y, con mayor precisión, respetar su contenido esencial. Así lo declara el artículo 19. $26^{\circ} \mathrm{CPR}$, cuando afirma que "los preceptos legales que por mandato de la Constitución regulen o complementen las garantías que ésta establece o que las limiten en los casos en que ella lo autoriza, no podrán afectar los derechos en su esencia, ni imponer condiciones, tributos o requisitos que impidan su libre ejercicio”.

Esta pretensión encuentra una garantía de eficacia en el artículo $1^{\circ} \mathrm{CPR}$, donde se declara que el "Estado está al servicio de la persona humana y su finalidad es promover el bien común, para lo cual debe contribuir a crear las condiciones sociales que permitan a todos y a cada uno de los integrantes de la comunidad nacional su mayor realización espiritual y material posible, con pleno respeto a los derechos y garantías que esta Constitución establece.”

\footnotetext{
${ }^{2}$ Por todas, RCS de 28 de noviembre de 2017, ROL:6885-17.

${ }^{3}$ Su relevancia es tal que "siguiendo la doctrina de la eficacia horizontal de todos los derechos fundamentales, tal derecho no se encuentra subordinado a su desarrollo legislativo, al derivar directamente de la propia Constitución", como señala Lanata Fuenzalida, G., "El derecho de los trabajadores a la seguridad y salud en el trabajo como derecho fundamental”, Cincuenta años de la Sociedad Chilena de Derecho del Trabajo y de la Seguridad Social, Rojas Miño, I., (Coord.), Santiago de Chile, Legal Publishing, 2011, p. 365.

${ }^{4}$ Declaración Prevención de la OISS, suscrita en Santiago de Chile el 3 de abril de 2009 (www.oiss.org).
} 
En esta materia, lo que está en juego es el derecho fundamental de la persona a la vida y a la salud, razón por la cual el mandato de tutela no solo es perfectamente aplicable en las relaciones laborales, sino que, por las características ya señaladas, es incluso más intenso que en otros ámbitos.

En efecto, el ámbito empresarial, mediante el derecho a la libertad de empresa y el poder de dirección, disfruta de un régimen jurídico de amplia libertad prestacional que, en modo alguno, debe confundirse con una cesión de los derechos del trabajador a la vida y a la salud que los convierta en ineficaces ${ }^{5}$. La protección de los derechos constitucionales tiene en la empresa, por tanto, la misma eficacia que en cualquier otro espacio social, como normas que se pueden invocar directamente ante los órganos judiciales, también en las relaciones privadas ${ }^{6}$. Se desprende de esta idea la existencia de un compromiso, el de velar porque en su espacio físico y en el desarrollo de su actividad se tutelen los derechos humanos, en especial el derecho a la vida. La propia Constitución de la Organización Internacional del Trabajo (en adelante, OIT) declara que "la responsabilidad del empleador respecto de la seguridad y salud de los trabajadores a su servicio es un principio fundamental de toda legislación laboral, basado en la lógica del contrato de trabajo" 7 .

La realidad obliga a proporcionar racionalidad al tráfico jurídico contractual, donde el Derecho ha de superar la tensión "entre las inquietudes del poder económico por proteger sus intereses y la tutela de los derechos humanos de los trabajadores y las trabajadoras" ${ }^{\text {. }}$ En el replanteamiento dogmático de la eficacia “inter-privatos” de los derechos fundamentales, se considera que en el contrato de trabajo se ponen en juego la persona del trabajador, su libertad y su dignidad, razón por la cual las normas laborales deben

\footnotetext{
${ }^{5}$ En sentido similar, González Labrada, M., Seguridad y salud en el trabajo y responsabilidad contractual del empresario, CEDECS 1996, pp. 105 ss.

${ }^{6}$ La vía utilizada por el Tribunal Constitucional español para asegurar esa eficacia ha sido la de considerar aplicables directamente los preceptos constitucionales que reconocen los derechos fundamentales como normas que se pueden invocar directamente ante los órganos judiciales, también en las relaciones privadas, por todos, Rodríguez Piñero, M., "La integración de los derechos fundamentales en el contrato de trabajo", en El modelo social de la Constitución Española de 1978 (Sempere Navarro, A., Director), MTAS, Madrid, 2003, p. 208.

${ }^{7}$ OIT, Normas de la OIT sobre seguridad y salud en el trabajo. Promover la seguridad y la salud en el medio ambiente de trabajo, OIT Ginebra 2009, pp. 4 y 5. La responsabilidad del empleador surge con motivo del contrato de trabajo, dice la RCSC, Resolución n ${ }^{0}$ 32411, Sala Cuarta, 14 de diciembre de 2006.

${ }^{8}$ Conferencia Internacional del Trabajo, Informe III (Parte 1B). Trabajadores migrantes. Tercer punto del orden del día: Informaciones y memorias sobre la aplicación de convenios y recomendaciones. Estudio general sobre el Convenio sobre los trabajadores migrantes (revisado), 1949 (número 97) y la Recomendación (número 86) y el Convenio sobre los trabajadores migrantes (disposiciones complementarias), 1975 (número 143) y la Recomendación (número 151). Informe de la Comisión de Expertos en Aplicación de Convenios y Recomendaciones (artículos 19, 22 y 35 de la Constitución), Organización Internacional del Trabajo $87^{\mathrm{a}}$ reunión, Ginebra, junio de 1999, p. 17, http://www.ilo.org/public/spanish/standars/relm/ilc/ilc87/r3-1b.htm
} 
proteger los derechos fundamentales a ella vinculados ${ }^{9}$ frente a intrusiones provenientes del medio empresarial, tal y como declara el artículo 2 del CT, al afirmar que "las relaciones laborales deberán siempre fundarse en un trato compatible con la dignidad de la persona”.

Esta problemática no puede tratarse, por tanto, en términos de neutralidad, salvo que el ordenamiento jurídico laboral quiera situarse fuera de contexto, lo que sería un síntoma evidente de su ineficacia e impediría su utilidad "como mecanismo de equilibrio material entre los derechos fundamentales del trabajador y la libertad de empresa" ${ }^{10}$.

Este equilibrio es parte de la función misma del Derecho del Trabajo y, como tronco del que nace, del ordenamiento jurídico preventivo, aun cuando ya se dice que empieza a germinar como una nueva disciplina jurídica ${ }^{11}$. Si la relación laboral tiene como efecto típico la sumisión de ciertos aspectos de la actividad humana a los poderes empresariales, el reto está en encontrar el punto de coordinación entre el interés del trabajador y el de la empresa $^{12}$.

La operación jurídica que a estos efectos se realiza es el juicio de proporcionalidad, instrumento de ponderación de los bienes jurídicos en juego y medida de corrección aplicable a todas las hipótesis de desequilibrio ${ }^{13}$, con aplicación del principio de proporcionalidad de los sacrificios” ${ }^{14}$, tarea ponderativa de extrema dificultad a la vista de los bienes jurídicos implicados.

\footnotetext{
${ }^{9}$ Cruz Villalón, J, “Los derechos constitucionales de los trabajadores extranjeros”, en Las transformaciones del Derecho del Trabajo en el marco de la Constitución Española. Estudios en homenaje al Profesor Miguel Rodríguez-Piñero y Bravo Ferrer, AA.VV., La Ley, Madrid, 2006, p. 549.

${ }^{10}$ Fernández López, M.F., Libertad ideológica y prestación de servicios, Relaciones Laborales 7/1985, p. 61; Blat Gimeno, F.R., Relaciones laborales en las empresas ideológicas, MTSS, Madrid 1986, p. 50.

${ }^{11}$ Valdeolivas García, Y., "Las fuentes del deber de seguridad: obligación contractual y desarrollo normativo", en AA.VV., Cuadernos de Derecho Judicial. Ley de Prevención de Riesgos Laborales. Últimas reformas y análisis de la normativa específica en la materia. Madrid (CGPJ), 2006, p. 20, dice que "lo que dota de autonomía a un determinado bloque normativo es la existencia de un conjunto de principios, caracteres y finalidades que la distinguen de otras ramas del ordenamiento jurídico".

${ }^{12}$ STC 99/1994, de 11 de abril, FJ 7.

${ }^{13}$ En este sentido, Terradillos Ormaetxea, E., El poder disciplinario empresarial. Principios y garantías, Tirant lo Blanch, Valencia 2004, p. 141. Así, de un lado, "el empresario no puede ampararse en la libertad de empresa para hacer ilusorios los derechos fundamentales del trabajador (SSTC 88/1985, de 19 de julio; 4/1996, de 16 de enero; 106/1996, de 12 de junio; 204/1997, de 25 de noviembre; 197/1998, de 13 de octubre; 98/2000, de 10 de abril; 80/2001, de 26 de marzo; 20/2002, de 28 de enero; 126/2003, de 30 de junio). Pero, de otro lado, la invocación de los derechos fundamentales del trabajador no puede justificar la imposición de modificaciones de la relación laboral, la ruptura del marco normativo de la misma o el incumplimiento de los derechos laborales que incumben al trabajador (STC 88/1985, de 19 de julio; 6/1988, de 21 de enero; 129/1989, de 17 de julio): el ejercicio de los derechos fundamentales por parte del trabajador no puede implicar una modificación unilateral de las obligaciones asumidas en el contrato (STC 6/1988, de $21 \mathrm{~d}$ enero), porque los derechos fundamentales no son ilimitados (STC 88/1985, de 19 de julio) y el ejercicio de los mismos ha de llevarse a cabo sin rebasar los límites que para ello se establezcan (SSTC 6/1988, de 21 de enero y 128/1990, de 5 de julio)".

${ }^{14}$ Rodríguez Piñero, M., ob. cit. 2003, p. 219-220.
} 
Lo que se exige a los poderes públicos (artículo $1 \mathrm{CPR}$ ) es, dada la posición preeminente de los derechos fundamentales, que la modulación se produzca en la medida estrictamente imprescindible. El correcto y ordenado respeto de los derechos fundamentales de trabajador ${ }^{15}$ requiere que se legislen, ejecuten ${ }^{16} \mathrm{y}$, en honor a la tutela judicial efectiva, interpreten y apliquen las normas preventivas de acuerdo a su verdadera finalidad ${ }^{17}$.

El contenido esencial del derecho a la vida, como se verá más adelante, se configura en la medida en que se obliga a no poner en peligro la salud del trabajador. La existencia de un riesgo laboral es, a veces, imposible de evitar. Lo que el contenido esencial exige es que, aun cuando el riesgo exista, sus consecuencias lesivas desaparezcan, algo que hoy día es, desde un punto de vista técnico, casi siempre posible.

${ }^{15}$ Palomeque López, M.C., "Derechos fundamentales y relación laboral", en El modelo social de la Constitución Española de 1978 (SEMPERE NAVARRO, A., Director), MTAS, Madrid, 2003, p.230.

${ }^{16}$ No es una práctica común la posibilidad de acudir a la figura de la inconstitucionalidad por pasividad del Legislador; sobre las limitaciones a esta figura vid. Prieto Sanchís, L., "Los derechos sociales y el principio de igualdad sustancial", en La universalidad de los derechos sociales: el reto de la inmigración, Tirant lo Blanch / PUV, Valencia 2004, pp. 111 ss. La experiencia constitucional lationamericana más moderna es interesante en este sentido, como destaca Echeverri Uruburu, A., "Los derechos sociales como derechos subjetivos fundamentales”, en IUSTA 29/2008, Universidad Santo Tomás, Bogotá, p. 70, donde afirma que aun cuando la Corte Constitucional colombiana "ha considerado que carece de competencia para conocer demandas de inconstitucionalidad por omisión legislativa absoluta, ..., a través de la figura de las condiciones o circunstancias inconstitucionales en casos específicos, como la situación de hacinamiento e insalubridad del sistema carcelario o en el de la población de cerca de 3 millones de desplazados por la violencia, ha buscado forzar al Gobierno para la adopción de medidas administrativas orientadas a superar tales condiciones de abierta contrariedad con los valores y principios de la Constitución”; del mismo modo, recoge las experiencias de otros países, como Brasil, donde en la "Constitución de 1980 se consagró el mandato de injunción, acción particular a través de la cual la omisión legislativa impugnada y que afecta la protección de derechos y libertades constitucionales es suplida por una orden judicial que produce efectos estrictamente inter pares"; o en Argentina, país en el que "al amparo de sus constituciones federales se ha ido desarrollando una jurisprudencia de precedentes a favor de la figura de la inconstitucionalidad por omisión”. La Constitución de la República Bolivariana de Venezuela, en su artículo 336.7, atribuye a la Sala Constitucional del Tribunal Supremo de Justicia la potestad para "declarar la inconstitucionalidad del poder legislativo municipal, estatal o nacional, cuando haya dejado de dictar normas o medidas indispensables para garantizar el cumplimiento de la Constitución, o las haya dictado en forma incompleta y establecer el plazo y, de ser necesario, los lineamientos de corrección”, considerando el artículo 22 que "la falta de ley reglamentaria de estos derechos no menoscaba el ejercicio de los mismos".

${ }^{17}$ La tutela judicial efectiva es "el derecho estrella del firmamento judicial”, según Díez-Picazo Y Ponce De León, L., Notas sobre el derecho a la tutela judicial efectiva, en Estudios de derecho y hacienda, 1/1987, pp. 29-42; sobre el particular, entre otros, Baylos Grau, A., La igualdad de las partes en el proceso laboral y la tutela judicial efectiva, Derecho privado y Constitución 4/1994 (Monográfico sobre la tutela judicial efectiva y el proceso de trabajo), pp. 107-130; Casas Baamonde, Ma Y Valdés Dal-Re, F., Tutela judicial, competencia de la jurisdicción social y acceso al proceso de trabajo, Derecho privado y Constitución, 4/1994 (Monográfico sobre la tutela judicial efectiva y el proceso de trabajo), pp. 11-70; Cavas Martínez, F., Supuesta vulneración del derecho a la tutela judicial efectiva: inimputabilidad de los defectos procesales denunciados a acción u omisión del órgano judicial, Revista Española de Derecho del Trabajo, 66/1994, pp. 631-644; Figueruelo Burrieza, A., Tutela Judicial efectiva y sistema constitucional de fuentes del derecho, en Los derechos fundamentales y libertades públicas (II) / XIII Jornadas de Estudio, Dirección General del Servicio Jurídico del Estado, Vol. 1/1993, pp. 115-126; Gil-Robles Y Gil-Delgado, A., Los nuevos límites de la tutela judicial efectiva, Centro de Estudios Constitucionales, 1996; Martín Valverde, A., Jurisdicción social y tutela judicial efectiva, Derecho privado y Constitución, 4/1994 (Monográfico sobre la tutela judicial efectiva y el proceso de trabajo), pp. 71-88; Sáez Lara, C., La tutela judicial efectiva y el proceso laboral, Civitas, 2004. 


\subsection{Las normas internacionales}

El preámbulo de la Constitución de la Organización Internacional del Trabajo (en adelante, OIT) dispone que "la protección del trabajador contra las enfermedades, sean o no profesionales, y contra los accidentes de trabajo es un elemento fundamental de la justicia social”. Al mismo tiempo, la Declaración de Filadelfia de 1944 establecía, como principio fundamental de la OIT, la imposibilidad de considerar el trabajo como una mercancía, afirmando de igual modo el derecho a unas condiciones de trabajo decentes y a un medio ambiente de trabajo seguro y saludable, mandato ratificado en la Declaración de la OIT sobre la justicia social para una globalización equitativa ${ }^{18}$. La OIT, de un modo consecuente con estas proclamas, dedica cerca del 80\% de todas sus normas e instrumentos, total o parcialmente, a la seguridad y salud en el trabajo (en adelante, SST), desde su creación en $1919^{19}$.

Al mismo tiempo, la OIT, como parte del Sistema de Naciones Unidas, elabora sus normas en relación con la propia Declaración Universal de los Derechos Humanos (artículos 3 y 23) y con el Pacto Internacional de Derechos Económicos, Sociales y Culturales (artículo 7), cuyas previsiones imponen también el debido respeto a la seguridad y salud de las personas en el ejercicio de su prestación laboral.

a) La extensa lista de normas internacionales del trabajo sobre prevención de riesgos tienen un rasgo característico: la mayoría de las ocasiones instruyen sobre qué hacer ante determinados riesgos o actividades que, por su peligrosidad, necesitan una especial atención.

Con todas ellas se edifica una normativa de referencia, al tener los Convenios el carácter de norma mínima mejorable a favor de los trabajadores por la norma nacional (artículo 19.8 Constitución de la OIT). Se diseña así un “marco mínimo de seguridad”, inviolable e indisponible in peius en los ordenamientos jurídicos internos y, por tanto, de respeto obligatorio para los poderes públicos, incluido el Poder Judicial.

Las normas internacionales del trabajo realizan una doble aportación de gran valor. De un lado, concretan las obligaciones exigibles en diferentes ámbitos productivos. De otro, auxilian al técnico de prevención con instrucciones cualificadas, favoreciendo un mayor rigor en la eficacia de las medidas preventivas.

\footnotetext{
${ }^{18}$ Declaración de la OIT sobre la justicia social para una globalización equitativa, Conferencia Internacional del Trabajo, 97ª reunión, Ginebra, 10 junio de 2008.

${ }^{19}$ Cómputo que efectúa la propia OIT (2009), p.1. En general, sobre las normas internacionales del trabajo, conviene tener presente el clásico trabajo de Válticos, Derecho internacional del trabajo, Tecnos 1977. También a Montt Balmaceda, M., Principios de Derecho Internacional del Trabajo. La OIT, Editorial Jurídica de Chile 1998.
} 
Aunque también es cierto que se encuentra en ellas una doble limitación: el de su naturaleza específica y el de su carácter técnico. En efecto, en el primer aspecto, hay que tener en cuenta que son normas que protegen a determinados colectivos, se refieren a riesgos muy concretos o a ciertas actividades productivas; en el segundo aspecto, hay que considerar que hacen observaciones dirigidas al tratamiento técnico de determinadas situaciones de "inseguridad", aportando pautas de comportamiento para definir qué medidas deberán adoptarse en cada caso.

Es por ello que, sin poner en duda la enorme contribución de estas normas internacionales, planteaban determinadas insuficiencias que exigieron de la OIT un salto cualitativo, porque muchas actividades preventivas e incontables colectivos de trabajadores no disponían de regulación internacional, ni nacional.

A la vez, y quizás como consecuencia, se generó la errónea impresión de que cuando nada se decía sobre un riesgo específico no se adquiría ningún compromiso para su eliminación. De este modo, se fue generando la convicción de que, si no hay norma específica, no hay obligación. No cabe duda de que este axioma es falso de toda falsedad. La aplicación al ámbito laboral del principio civil alterum non laedere exige que la actividad productiva no lesione, no dañe, no deteriore la salud de la persona que trabaja. La seguridad y salud en el trabajo hay que entenderla como "la ciencia de la anticipación, el reconocimiento, la evaluación y el control de los riesgos derivados del lugar de trabajo o que se producen en el lugar de trabajo que pueden poner en peligro la salud y el bienestar de los trabajadores, teniendo en cuenta su posible impacto en las comunidades cercanas y el medio ambiente en general” 20 .

Es por ello que la reducción de la protección del riesgo profesional al exclusivo aspecto de la reparación es absolutamente insuficiente en un modelo de Estado social y democrático. La compensación económica de la lesión, cómo única solución legal, es un mal en sí mismo, porque implica poner precio a la salud de la persona, a una integridad corporal que nunca se recupera del todo y que es siempre irrecuperable en caso de muerte.

Este enfoque global requería de una nueva intervención internacional, una nueva contribución de la OIT al Derecho del Trabajo, mediante un instrumento normativo de carácter general, basado en un proceso cíclico de elaboración, aplicación y revisión de una política que asegure que los sistemas nacionales de SST mejoren de forma continua ${ }^{21}$.

Se produjo entonces un consenso internacional cuyas principales características son: un enfoque de SST para todos los trabajadores, independientemente del sector económico, tipo de trabajo (asalariado o autónomo), tamaño de la empresa o sociedad (industria, sector público, servicios, agricultura, etc.); la responsabilidad de los gobiernos para el

\footnotetext{
${ }^{20}$ Definición de la International Ocupational Hygiene Association (IOHA), www.ioha.net

${ }^{21}$ OIT (2009), p. 6.
} 
establecimiento de infraestructuras adecuadas para la práctica de la salud en el trabajo mediante la legislación, los convenios colectivos y cualquier otro mecanismo aceptable, previa consulta con las organizaciones representativas de los trabajadores y las empresas; la responsabilidad de los gobiernos con respecto al desarrollo y puesta en práctica de una política de seguridad y salud en el trabajo en colaboración tripartita con las organización de trabajadores y empresas; la responsabilidad primaria del empleador con respecto a la prestación de servicios de salud en el trabajo a nivel de empresa; la prevención de los accidentes de trabajo y las enfermedades profesionales y el control de los peligros del lugar de trabajo, así como el desarrollo de un medio ambiente de trabajo y un trabajo que favorezcan la salud de los trabajadores, un ámbito que no solo cubre la seguridad y salud, sino también el bienestar psicológico y social y la capacidad de llevar una vida social y económicamente productiva ${ }^{22}$.

Con esta finalidad se elaboran el Convenio 155 OIT (C155OIT) y la Recomendación 164 OIT (R164OIT), ambos de $1981^{23}$, concediendo la prioridad a la prevención y siendo la protección el último recurso que ha de utilizarse cuando no se pueda evitar, minimizar o eliminar la exposición a riesgos, en la aplicación de una política centrada en la prevención más que en la reacción a las consecuencias de los accidentes y enfermedades del trabajo ${ }^{24}$.

La característica más relevante del C155OIT y de la R164OIT se concreta en que son instrumentos amplios y globales, tanto en términos de su alcance como de sus objetivos, donde se establece una obligación general de seguridad empresarial aplicable a todas las ramas de la actividad económica y a todos los trabajadores de estas ramas (artículo 1 C155OIT). Aunque admite algunas excepciones en su ámbito subjetivo, en base al principio de flexibilidad aplicativa, que han de ser justificadas por cada país.

La prevención y mejora continua del medio ambiente de trabajo definen la política nacional en SST, con cinco principales esferas de acción que concreta el artículo 4 del C155OIT: el control de los componentes materiales del trabajo; la adaptación del medio ambiente de trabajo a los trabajadores; la formación de las personas que participen en la actividad laboral; la comunicación y cooperación; y la protección de los trabajadores y sus representantes contra medidas disciplinarias.

Estas normas de carácter general se han visto acompañadas por el Convenio 187 sobre el marco promocional para la seguridad y salud en el trabajo de 2006, cuyo objetivo es

\footnotetext{
${ }^{22}$ FEDOTOV, SAUX Y RANTANEM, "Normas, principios y enfoques de los servicios de salud en el trabajo”, en Enciclopedia de salud y seguridad en el trabajo, $n^{\circ} 16$, servicios de salud en el trabajo, pp. 3 y 5.

http://www.insht.es/InshtWeb/Contenidos/Documentacion/TextosOnline/EnciclopediaOIT/tomo1/16.pdf

${ }^{23}$ Consecuencia de una actividad previa de la OIT que se concreta en el Programa Internacional para el Mejoramiento de las Condiciones y del Medio Ambiente de Trabajo de 1976 (PIACT). Van acompañados del Protocolo de 2002 relativo al Convenio sobre la seguridad y salud de los trabajadores 1981. Comentarios del Comité de Expertos en http://www.ilo.org/dyn/normlex/es/f?p=1000:20010:0::NO:::

${ }^{24}$ OIT (2009), p. 6.
} 
“promover la mejora continua de la seguridad y salud en el trabajo”, impulsando la adecuada aplicación de las normas internacionales en la materia.

Son numerosas las normas internacionales del trabajo que Chile ha ratificado. La última de ellas, el Convenio 187 de 2006, que acompaña a un buen número de normas de carácter técnico y específico. No procede ahora entrar en el polémico asunto del control de convencionalidad de las normas internacionales y su lugar en la jerarquía normativa. Lo cierto es que la inclusión de todas ellas en el ordenamiento jurídico chileno determina, sin ningún género de duda, una serie de compromisos jurídicos que sitúan la exigencia preventiva de las normas laborales chilenas en un nivel protector básico.

Ello no obstante, la principal norma de obligaciones generales, el C155OIT, sigue sin ser ratificada por Chile. Quizás pueda parecer una circunstancia menor, a la vista de la actual legislación chilena. Sin embargo, esta afirmación no es del todo cierta.

La ventaja que supone ratificar el C155OIT para la defensa del derecho a la vida y a la salud en el trabajo es significativa. De un lado, en cuanto a los compromisos que implica en relación al despliegue de determinadas políticas públicas. De otro, a los efectos de su ámbito subjetivo, debido a que la universalidad de la protección haría inviable una legislación restrictiva, más allá de las excepciones que el propio Convenio establece. Y, en fin, respecto del contenido del deber de seguridad, algunos de cuyos rasgos característicos están definidos en el Convenio.

b) En el contexto americano, la Carta Democrática Interamericana ${ }^{25}$, dice en su artículo 10 que "la promoción y el fortalecimiento de la democracia requieren el ejercicio pleno y eficaz de los derechos de los trabajadores y la aplicación de normas laborales básicas, tal como están consagradas en la Declaración de la Organización Internacional del Trabajo (OIT) relativa a los Principios y Derechos Fundamentales en el Trabajo y su Seguimiento, adoptada en 1998, así como en otras convenciones básicas afines de la OIT. La democracia se fortalece con el mejoramiento de las condiciones laborales y la calidad de vida de los trabajadores del Hemisferio". Reiterando en su artículo 13 que "la promoción y observancia de los derechos económicos, sociales y culturales son consustanciales al desarrollo integral, al crecimiento económico con equidad y a la consolidación de la democracia en los Estados del Hemisferio”.

La Convención Americana sobre Derechos Humanos (Pacto de San José) ${ }^{26}$ recuerda, en su artículo 4.1 que toda persona tiene derecho a que se respete su vida y en el artículo 5.1 que toda persona tiene derecho a que se respete su integridad física, psíquica y moral. Lo que concreta, en el Protocolo Adicional a la Convención Americana sobre Derechos Humanos en materia de Derechos Económicos, Sociales y Culturales (Protocolo de San

\footnotetext{
${ }^{25}$ Aprobada en la primera sesión plenaria, celebrada el 11 de septiembre de 2001.

${ }^{26}$ San José, Costa Rica 7 al 22 de noviembre de 1969.
} 
Salvador), al reconocer, en su artículo 7, que el derecho al trabajo supone que toda persona goce del mismo en condiciones justas, equitativas y satisfactorias; para cumplir con este mandato los Estados garantizarán, en sus legislaciones nacionales, de manera particular, la seguridad e higiene en el trabajo, la prohibición de trabajo nocturno o en labores insalubres o peligrosas a los menores de 18 años y, en general, de todo trabajo que pueda poner en peligro su salud, seguridad o moral; la limitación razonable de las horas de trabajo, tanto diarias como semanales, teniendo en cuenta que las jornadas serán de menor duración cuando se trate de trabajos peligrosos, insalubres o nocturnos; así como el derecho a que el descanso, el disfrute del tiempo libre y las vacaciones sean remuneradas, del mismo modo que los días feriados nacionales.

\subsection{Las normas legales y reglamentarias}

Estos antecedentes internacionales permiten disponer en el marco normativo nacional de la prevención de riesgos, como se comentó, de una plataforma jurídica, a modo de derechos mínimos e invulnerables, que las normas nacionales sólo podrán mejorar. La relevancia de las normas internacionales va a depender del esmero que la legislación chilena dedique a tutelar el derecho a la vida y a la salud en el trabajo: si las normas preventivas chilenas mejoran este régimen jurídico básico, las normas internacionales servirán de apoyo hermenéutico; en caso contrario, las normas internacionales del trabajo, una vez incorporadas, configuran auténticos derechos subjetivos que se incorporan ope legis al contrato de trabajo.

Lo ideal es que las normas internacionales sean una pequeña parte del ordenamiento jurídico preventivo moderno, en el que es frecuente observar un cuadro normativo de cierta envergadura, tanto por su agudeza cualitativa, como por su longitud cuantitativa.

El precepto legislativo central en el ordenamiento jurídico preventivo chileno es el artículo 184 del CT. En él se encuentra, como señalé, el deber de seguridad empresarial, también denominada deuda de seguridad u obligación general de seguridad, en virtud del cual el empresario debe a sus trabajadores una “protección eficaz” en el trabajo.

Como se observa, la expresión "protección eficaz" es indicativa de lo que va a ser una constante en las obligaciones preventivas: su ambigüedad, su configuración a través de conceptos jurídicos indeterminados. A este enunciado acompañan otros muchos de grafía similar, como "medidas necesarias", "en la medida razonable y posible”, "posibles riesgos”, “condiciones adecuadas”, "peligro grave e inminente”... Es por ello que entender el alcance real de las obligaciones preventivas no es una tarea hermenéutica sencilla, a la hora de puntualizar, con certeza, qué es lo que debe el empresario en seguridad a sus trabajadores.

La razón que persigue el legislador, con este uso conceptual impreciso, no es, qué duda cabe, proporcionar inseguridad jurídica. Aun cuando igual que en el derecho comparado 
es frecuente padecer ciertas carestías en la técnica legislativa, podría ser que, en este caso, la falta de esmero no sea la causa. El motivo más plausible, para justificar el uso de expresiones tan abiertas, parece encontrarse en la necesidad de abarcar la infinitud de situaciones posibles, de modo tal que ninguna quede ajena a la obligación de $\operatorname{proteger}^{27}$. Claro que esta generosa visión del quehacer legislativo no siempre es compartida, solicitándose en no pocas ocasiones una mayor precisión que contribuya a clarificar las conductas exigibles.

La solución encontrada es recurrir a pautas de conducta, para poder ir definiendo cuál es el “estándar de comportamiento”. Esta tarea dependerá de cómo se concreten las diferentes obligaciones, así como al esfuerzo de conceptualización que hagan las leyes y reglamentos que acompañan al 184CT. La misión está en concretar, con la mayor precisión posible, qué actividad preventiva debe desplegar el empresario para cumplir con su obligación contractual y qué resultado se espera de ella.

En esta línea argumental, puede decirse que el ordenamiento preventivo chileno es, en términos generales, adecuado desde un punto de vista técnico. Sin embargo, esta actividad normativa es menos fructífera cuando se trata de concretar obligaciones que especifiquen la pauta de conducta empresarial: planificación preventiva, organización técnica, protección de la maternidad o de situaciones de especial sensibilidad, participación, vigilancia de la salud... Así como al definir los principios preventivos que, al integrarse en cada obligación, facilitan al intérprete la actividad de encontrar soluciones más equitativas.

La significativa ausencia de estas obligaciones justifica la propuesta de reforma que se encuentra en la Cámara de Diputados ${ }^{28}$, cuya pretensión es modificar el CT y la LAT, manteniendo la multiplicidad actual de fuentes legales protagónicas, repartiendo las obligaciones preventivas cardinales entre el CT, la LAT y el Código sanitario, aunque este último más en relación a su desarrollo reglamentario que en sí mismo ${ }^{29}$.

Por su parte, el Código del Trabajo dispone de una amplia gama de artículos referidos a la materia. El 184CT es el punto de referencia en torno al cual giran todos los demás, cuando se trata de integrar el contenido de la protección eficaz debida al trabajador ${ }^{30}$. Empezando por el artículo 1CT, al señalar la aplicación de esta norma a los empleados

\footnotetext{
${ }^{27}$ Valdeolivas García, Y., ob. cit. (2006), p. 22.

${ }^{28}$ Que ingresó en la Cámara el 9 de mayo de 2013 a través del Mensaje Presidencial nº 068-361, Boletín 8971-13. Recoge buena parte de las propuestas de la Estrategia Iberoamericana de Seguridad y Salud 20102013 y del Informe para la Comisión Asesora Presidencial para la Seguridad en el Trabajo del Gobierno de Chile, de 24 de septiembre de 2010.

${ }^{29}$ El Proyecto de Ley hace referencia a la multiplicidad de normas e instituciones en la materia y aboga por crear un sistema integrado de seguridad y salud en el trabajo, Considerando 6.

${ }^{30}$ Por sus implicaciones en la dignidad, la vida y la salud, se dice que este derecho tiene una "base segura y fuerte”, Rojas Miño, I. Manual de Derecho del Trabajo, Santiago de Chile, Lexis-Nexis, 2004, pp. 173174.
} 
públicos, cuando no esté regulado en sus respectivos estatutos, lo que no ocurre en la actualidad; o el artículo 2CT, referido a la protección frente al acoso laboral; los artículos 13CT y siguientes sobre edad de trabajar y sus limitaciones; los artículos 21CT y siguientes sobre jornada de trabajo y 35 y siguientes del CT sobre descanso; los artículos 183A y siguientes del CT sobre trabajo en régimen de subcontratación y 183I de empresas de servicios transitorios y el trabajo de puesta a disposición, entre otros, teniendo en cuenta la posibilidad de utilizar el procedimiento de tutela laboral regulado en los artículos 485 y siguientes del CT.

Como decía, el CT va acompañado de la LAT, no solo porque ambas normas legales son protagonistas del sistema preventivo, sino porque, además, el propio artículo 210 del CT reitera el cumplimiento de las obligaciones empresariales que la LAT contiene. Esta norma, a pesar de estar dirigida eminentemente a regular las prestaciones económicas, incorpora también ciertas obligaciones preventivas. En efecto, los artículos 65 y siguientes de la LAT son imprescindibles para la comprensión jurídica de aspectos preventivos tan diferentes como los comités paritarios, el reglamento de seguridad e higiene, la coordinación de actividades empresariales, la clausura en caso de riesgo inminente, la reclamación por daños y perjuicios o los derechos de traslado en caso de enfermedad profesional.

El cuadro preventivo legal que acabo de describir viene acompañado por un buen número de normas reglamentarias que completan el marco legal. Algunas tienen un ámbito genérico, como el Decreto Supremo no 40 de 1969 que desarrolla el Reglamento sobre prevención de riesgos laborales o el Decreto $n^{0} 594$ del año 2000 sobre condiciones sanitarias y ambientales en los lugares de trabajo. Otras desarrollan obligaciones específicas, como el Decreto 76 de 2007 que desarrolla el artículo 66bis de la LAT respecto a la prevención en contratas y subcontratas, el Decreto ${ }^{\circ} 54$ de 1969 que regula los comités paritarios o el Decreto $\mathrm{n}^{\circ} 50$ de 2007 sobre las actividades peligrosas para menores, entre otros muchos a los que se irá haciendo referencia en este trabajo ${ }^{31}$.

Con todo, es trascendente señalar que el cuadro normativo no se agota en el CT o en la LAT y sus reglamentos. El ámbito material de la prevención se encuentra también en otras normas, sean estas laborales, de Seguridad Social o de otra naturaleza. Apoya esta afirmación la propia dicción de la deuda de seguridad y otras obligaciones preventivas, en las que se hace siempre eco de las expresiones "todas las medidas necesarias" o “condiciones adecuadas”. Su amplitud no puede sino hacer pensar en la aplicación de cualquier norma, del tipo que sea, necesaria para ofrecer la debida protección eficaz, esté especificado para ello y, como se verá, incluso cuando no lo está. El conjunto de

\footnotetext{
31 - Normas generales (Ley 18834, Ley 19345, Ley 20123, DS 101 1968, DS 40 1969, DS 54 1969, DS 168 1996, etc.) e instrumentos técnicos que se encargan de regular riesgos específicos (DS 594 1999, DS 20 2001, DS 148 2003, DS 63 2005, DS 76 2007, etc.) o colectivos especiales (DS 20 2001, DS 50 2007, etc.)
} 
disposiciones preventivas no está delimitado, como consecuencia, por su denominación o identificación formal, sino en la medida de que todo o parte de su contenido sea capaz de regular aspectos relacionados con la seguridad y salud en el trabajo ${ }^{32}$.

\section{EL ALCANCE DE LA DEUDA DE SEGURIDAD O ESTÁNDAR DE PROTECCIÓN}

La deuda u obligación general de seguridad constituye el punto normativo central de la protección preventiva: abre y cierra el conjunto del sistema, concreta la posición empresarial, se despliega en un conjunto de medidas específicas y permite que la tutela llegue donde las obligaciones reglamentarias no pueden llegar.

Sita en el artículo 184 del CT, exige al empresario que proporcione una protección eficaz al trabajador. Esta expresión plantea la necesidad de conocer qué protección se considera eficaz o, en otros términos, cuál es el esfuerzo preventivo exigible a la empresa.

La fórmula utilizada por el derecho europeo, que emana de la Directiva Marco, se expresa en términos casi miméticos a la norma chilena, solicitando el uso de todas las medidas necesarias para obtener la protección eficaz de los trabajadores en seguridad y salud. En este sentido, aunque cada contexto jurídico tenga sus peculiaridades e impida una transposición mutatis mutandis, para descifrar el alcance de la deuda de seguridad chilena podría ser útil tener una referencia comparada en las categorías europeas.

Ciertamente, aunque el derecho chileno sea menos explícito, los fundamentos conceptuales modernos de la seguridad y salud en el trabajo son los mismos. Y, desde un punto de vista técnico-científico, los expertos en prevención de riesgos laborales siguen pautas muy similares, tanto en el contexto laboral chileno como en el europeo, como se puede observar en las guías y manuales técnicos de entidades especializadas. De este modo, si la comprensión técnico preventiva se gestiona en términos de consenso, protegiendo las normas el mismo bien jurídico y teniendo un anclaje constitucional similar, parece sensato pensar que la interpretación de la deuda de seguridad será bastante semejante, más allá de que el legislador de uno u otro entorno le ponga más o menos mimo a la redacción.

Esta "delicadeza legislativa" se manifiesta, a la hora de concretar la trascendencia de la obligación de seguridad, con la inclusión de términos y conceptos claros que permitan

\footnotetext{
32 Esta es la orientación enunciada en el Proyecto de Ley, en diversas ocasiones, destacando la pretendida inclusión de un nuevo artículo 184A en el CT, donde, en el sentido señalado, expone que se entenderá por "normativa de protección y prevención de la seguridad y salud en el trabajo, toda norma legal o administrativa, emanada de un organismo con competencias o facultades en la materia, que tengan por objeto la prevención de los riesgos de accidentes de trabajo y enfermedades profesionales, y la eliminación o reducción de cualquier daño a la salud de los trabajadores que derive del desempeño de sus actividades”.
} 
una buena comprensión de la voluntad legislativa. Sirven con este fin los principios preventivos, al señalar pautas de comportamiento con las que determinar el alcance y contenido de obligaciones que tienen, muchas veces por necesidad, un carácter tan abierto como la deuda de seguridad ${ }^{33}$.

\subsection{La máxima eficacia consiste en evitar los riesgos}

La primera incertidumbre relevante que surge al leer la expresión "protección eficaz” se resume de un modo simple: ¿cuándo es eficaz la protección?, ¿cuál es el nivel de riesgo autorizado por la ley? No es el ánimo de este epígrafe inventar un problema jurídico. La duda es más real de lo que pueda parecer y forma parte de un debate constante, aunque bien es cierto que más en la academia y en los tribunales que entre los empleadores y técnicos de prevención. Esto significa que, en ocasiones, pasa desapercibida en la ejecución preventiva empresarial, generando errores de apreciación sobre el grado de cumplimiento de las obligaciones de los que solo se toma conciencia cuando es demasiado tarde, cuando ya se ha producido el accidente y deben asumirse las costosísimas responsabilidades que de dicha actitud se generan. Conviene por tanto hacer caso al adagio popular típico en la materia que dice "más vale prevenir que lamentar”. La respuesta a la pregunta de cómo se mide la eficacia de la protección permitirá determinar lo que se adeuda al trabajador en seguridad y conocer, con exactitud, qué medidas son necesarias para conseguir dicho objetivo.

Pues bien, por más que parezca obvio, resulta útil recordar algo que no siempre forma parte de una diligente apreciación preventiva: una cosa es anticiparse al riesgo y otra diferente evitar la lesión. Aun cuando, en el fondo, ambas puedan impedir que la vida y la salud se vean afectadas, contribuyen de un modo muy diferente. La segunda opción ignora, de un lado, el bienestar general, limitando sus efectos a la seguridad y prescindiendo de la salud, incumpliendo el considerando que justifica el DS 594 de 1999; de otro, como consecuencia, aumenta el índice de posibilidades de que la integridad del trabajador pueda verse deteriorada, al convivir con el riesgo laboral y aproximarlo a su persona. Por eso, estando ante obligaciones de riesgo, la tarea consiste en dilucidar cuál es el punto sobre el que ha de presionar esta contingencia productiva.

Una opinión muy frecuente es creer que, aun cuando el riesgo esté presente, la obligación se cumple evitando que tenga consecuencias sobre la salud y, por tanto, entender que "si

\footnotetext{
33 Sobre el particular, in extenso, ver Núñez González, C., Prevención de riesgos laborales en Chile. Alcance y contenido del artículo 184 del Código del Trabajo Santiago, Chile: Librotecnia, 2a Ed. 2014. En España, Igartua Miró, M.T., La Obligación General de Seguridad. Valencia, Tirant lo Blanch 2000 y Salcedo Beltrán, C., El deber de protección empresarial de la seguridad y salud de los trabajadores, Tirant lo Blanch 2000.
} 
no hay lesión, no hay infracción”34. Las cosas no son tan sencillas. La pretensión de las normas preventivas no se limita a impedir la actualización del riesgo, sino que pone el énfasis en su eliminación. Este es el modo en el que se logra la verdadera eficacia protectora, al desaparecer cualquier posibilidad de que se materialice un daño sobre el trabajador y, en su otra faceta, contribuyendo a que su salud no se deteriore por la actividad productiva, en un cumplimiento integral del principio alterum non laedere.

La prevención, por definición, según la RAE consiste en la preparación y disposición que se hace anticipadamente para evitar un riesgo, lo que le lleva a focalizar su proyección en un momento anterior a su propia existencia, a la posibilidad de que el riesgo desaparezca como elemento potencialmente lesivo; solo en su defecto, cuando no hay medios que puedan impedirlo, se ubica la protección en el espacio en el que dicho riesgo existe, debiendo evitar que se pueda manifestar a modo de lesión.

La secuencia de la deuda de seguridad se proyecta, de esta forma, de mayor a menor protección, expectativa que se mide en función de la posibilidad de que el riesgo exista y de la severidad de sus consecuencias si se materializa. El primer objetivo es el riesgo laboral que no existe, el que presenta menos posibilidades de actualización, alcanzando entonces la protección su máxima eficacia. El segundo es que el riesgo sea imposible de evitar, riesgo que será evaluado para medir e impedir sus consecuencias, mediante medidas colectivas que lo alejen al máximo de la persona y, cuando esto no sea posible, de medidas individuales que le ofrezcan la máxima protección. El tercero se mide en términos de probabilidad de actualización, cuando la eventualidad lesiva es más cierta y, llegado al límite, se reconoce como incompatible con la salud; esta situación se denomina peligro grave e inminente y, cuando se presenta, exige la paralización de la actividad productiva.

Este es el orden impreso en el derecho positivo, decisión que guía y orienta la conducta a seguir. Así se pronuncia, en general, el artículo 37 del DS 594 de $1999^{35}$, cuando decreta que “deberá suprimirse en los lugares de trabajo cualquier factor de peligro que pueda afectar la salud o integridad física de los trabajadores”36 o en el artículo 57 cuando dice que "el empleador será responsable de evitar que los trabajadores realicen su trabajo en condiciones de riesgo para su salud” ${ }^{37}$. En particular, el CT se refiere a evitar los riesgos

34 En este sentido se pronuncian también Contador Abraham, P. y Rodríguez De Los Ríos, M.F., "Vulneración del derecho a la vida e integridad física y psíquica de los trabajadores. Obligación de seguridad o deber de protección del empleador, no requieren la producción de un daño o accidente, para configurar su incumplimiento”, Revista de Derecho Laboral y Seguridad Social, Volumen IV N 6 , Santiago de Chile, Thomson Reuters, 2016.

35 Decreto Supremo n 594 aprueba el Reglamento sobre condiciones sanitarias y ambientales básicas en los lugares de trabajo.

${ }^{36}$ Este texto reglamentario no define qué entiende por peligro, aunque sí lo hace el artículo 2 del Decreto 50 (menores, $13 \mathrm{CT}$ ), en el que se identifica como toda actividad o forma de trabajo en el que las exigencias de las labores pueden interferir o comprometer el normal desarrollo físico, psíquico o moral de los menores. ${ }^{37}$ En el DS 594 de 1999, además de los expuestos en el texto, se habla de "evitar" riesgos en reiterados preceptos -15 , 33 o 51, por ejemplo- 
cuando regula situaciones especiales, como la manipulación de cargas -artículos 211 G y H CT-.

El Proyecto de Ley, en su Considerando 5, sigue esta línea, cuando solicita al empleador que la mejora del proceso productivo sea continua, identificando y evaluando los riesgos con objeto de evitarlos o controlarlos. Esta sucesión, primero evitar y, después, controlar, es coincidente con las normas internacionales y europeas. En ellas se exige que los riesgos evitables desaparezcan, si bien, siendo conscientes de que no siempre es posible eliminar todos los riesgos, se consiente la existencia controlada de riesgos compatibles con la actividad productiva. Estos riesgos se consideran legales, por su pervivencia en el trabajo; aunque conviene recordar que trabajar con riesgo viene a ser una cesión del derecho a la vida y a la integridad física, por lo que las cesiones que se realicen de este derecho estarán filtradas por el principio de proporcionalidad en el conflicto de derechos. La cesión del derecho a la vida y a la salud no podrá afectar el contenido esencial de los derechos constitucionales, tal y como expresa el artículo 19.26 CPR y el artículo 485CT en relación con el artículo 5 del CT, ante lo cual será imprescindible poner "todos los medios necesarios” para neutralizar sus consecuencias lesivas.

Esta actividad técnica se apoya, en el derecho europeo, en la regulación de los principios de la acción preventiva, hilo conductor de la actuación protectora. Entre ellos se encuentra el de "combatir los riesgos en su origen", clave para comprender que la actividad preventiva no es accesoria, sino que se integra en el proceso productivo. Este principio está operativamente vinculado al que exige anteponer la protección colectiva a la individual, justificado por razones de seguridad (aleja el riesgo de la persona, facilita la eficacia en el control de su funcionamiento), de comodidad (los equipos de protección individual -cascos, guantes, botas, trajes ignífugos- dificultan la actividad productiva) o de salubridad (son susceptibles de provocar reacciones en la salud del trabajador, como múltiples problemas dermatológicos). Quizás por ello el Proyecto de Ley entiende que las medidas de protección personal son la última barrera de defensa, debiendo ser todas ellas adecuadas al riesgo.

El objetivo final es evitar todo el riesgo que sea posible, utilizando las medidas necesarias $(184 \mathrm{CT})^{38}$. Aunque, al definir hasta dónde es "posible” evitar o reducir el riesgo se cuenta, junto con la exigencia al empresario, con la obligación contractual del propio trabajador de cooperar en su autocuidado ${ }^{39}$. De esta forma, las posiciones jurídicas de

\footnotetext{
${ }^{38}$ El Proyecto de Ley hace una referencia que acompaña lo que acabo de afirmar en el texto, al plantear en considerando 5.d) i- un proceso periódico de autoevaluación en toda empresa con más de 10 trabajadores, con el objetivo de ir mejorando el nivel de cumplimiento preventivo.

${ }^{39}$ El régimen de sanciones a este incumplimiento se fija en el reglamento interno por previsión del artículo 67LAT. A esta obligación, en el ordenamiento chileno, hace referencia Gajardo Harboe, M.C., "El deber de seguridad”, Revista Chilena de Derecho del Trabajo y de la Seguridad Social, Volumen 5, № 9, 2014. p.30. Sobre el deber de colaboración, en general, puede verse Núñez González, C., "El deber de colaboración del trabajador en la prevención de riesgos laborales”, Revista de Derecho Social 75/2016.
} 
empresario y trabajador están teleológicamente orientadas a obtener un mismo objetivo: conseguir el máximo nivel posible de seguridad y salud para el trabajador ${ }^{40}$.

Esta fórmula de ahuyentar el riesgo de la actividad productiva, hasta el máximo exponente, está vinculado a la proyección integradora de la seguridad y salud. Es imprescindible comprender que la actividad preventiva es una parte de la organización del trabajo, desde el inicio mismo de la concepción y planificación de la actividad productiva empresarial, en modo alguno una actividad accesoria de la misma.

El límite a la compatibilidad productiva se encuentra en el denominado peligro grave e inminente, situación que puede sobrevenir durante la prestación laboral y que da lugar a la paralización productiva. En el derecho europeo se plantea, además de como obligación empresarial o facultad de las autoridades correspondientes, como un derecho individual y/o colectivo de los trabajadores, a modo de derecho de resistencia, debido al bien jurídico tutelado. Se admite así que ante la apreciación de un peligro grave e inminente los trabajadores puedan paralizar la actividad productiva, incluso contra la orden empresarial, teniendo como límite la negligencia o la mala fe.

La paralización en Chile procede, en la versión histórica del artículo 76 de la LAT, cuando hay un accidente de trabajo fatal ${ }^{41}$, entendiendo por tal el que provoca la muerte del trabajador de forma inmediata o durante su traslado a un centro asistencial; así como cuando el accidente es grave, definido como cualquiera que obligue a realizar maniobras de reanimación, obras de rescate u ocurra por caída de altura de más de dos metros o provoque, en forma inmediata la amputación o pérdida de cualquier parte del cuerpo o involucre un número tal de trabajadores que afecte al desarrollo normal de la faena afectada $^{42}$. La paralización a la que de un modo expreso bien obligado el empresario es, de esta forma, ex post, una vez ya se ha materializado el accidente y provocado una lesión o daño al trabajador, siempre y cuando sea durante el tiempo de trabajo ${ }^{43}$.

Sin embargo, esta regulación fue actualizada en 2017 con la incorporación del artículo 184bis $\mathrm{CT}^{44}$, de clara naturaleza preventiva, con dos actuaciones complementarias: la del empresario y la del trabajador. En efecto, este precepto exige que cuando exista un riesgo grave e inminente para la vida o salud de los trabajadores, el empleador deberá informar de su existencia y suspender de manera inmediata las faenas afectadas, evacuando el lugar

\footnotetext{
${ }^{40}$ Gütiérez-Solaz Calvo, B., El deber de seguridad y salud en el trabajo, CES, 1999, p. 97.

${ }^{41}$ La naturaleza del accidente es inescindible de la obligación, por cuanto que un accidente no laboral no da lugar al aviso que produciría la paralización, según la SCA Talca, Res. nº 7821, Rec. 126/2009, aunque, a mi juicio, habría que ser cautos en la medida en que no siempre es fácil, a simple vista, conocer la etiología de la fatalidad.

${ }^{42}$ Circular $n^{\circ} 2345$ de 10 de enero de 2007 de la Superintendencia de Seguridad Social.

${ }^{43}$ La SCA Valparaíso nº 62662 de 24 diciembre 2010, Rec. 467/2010 llegó a plantear la improcedencia de paralizar, aunque existieran condiciones objetivas, una vez finalizada la jornada.

${ }^{44}$ Ley 21012 de 9 de junio de 2017.
} 
cuando sea necesario $^{45}$. Ahora bien, esta importante obligación añade una previsión de extrema relevancia, al reconocer el derecho al trabajador de interrumpir sus labores y abandonar el lugar de trabajo cuando, por motivos razonables, considere que continuar con ellas implica un riesgo grave e inminente; en este caso, deberá informar de inmediato al empleador, sin que pueda sufrir perjuicio o menoscabo alguno por la adopción de dicha medida.

Esta nueva disposición se vincula a la contenida en el artículo 68 LAT, que faculta al Servicio Nacional de Salud a clausurar las fábricas, talleres, minas o cualquier sitio de trabajo que signifique un riesgo inminente para la salud de los trabajadores o de la comunidad. Así como también lo es la paralización regulada en el artículo 28 de decreto con fuerza de ley No 2, de 1967 del Ministerio del Trabajo y Previsión Social, contempla la facultad de los Inspectores del Trabajo para ordenar la suspensión inmediata de las labores que, en su opinión, constituyen peligro inminente para la salud o vida de los trabajadores.

\subsection{La razonabilidad técnica como estándar de protección}

La segunda gran incertidumbre que presenta la deuda de seguridad es conocer la lógica operativa con la que se obtiene la "máxima protección posible”. Dicho de otro modo, una vez decidido que la línea de meta es el riesgo cero y que la obligación consiste en llegar lo más cerca que se pueda, la pregunta es cuándo se alcanza lo “posible” en seguridad y salud laboral.

Una opción, la que tiene un tinte más mercantil, consiste en vincular los requerimientos legales con la capacidad económica del empleador. De este modo, la máxima protección posible será aquello que los recursos financieros permitan alcanzar a la empresa. La aproximación a la protección eficaz se realizaría desde lo crematístico, parámetro que determinaría la razonabilidad de la medida y aquello que sería exigible al empresario. La vida y la salud de cada trabajador se vincularían a la solvencia pecuniaria de la empresa en cada momento.

Otro juicio, de tinte más laboral, considera que la vida y la salud no pueden estar pendientes de la capacidad económica de cada empresa. El bienestar de los trabajadores es la finalidad de la "seguridad laboral", según se declara en el considerando justificativo del DS 594 de 1999 y así lo ratifica la nueva pretensión legislativa, ahora en debate parlamentario. Desde este juicio, la protección eficaz se obtiene con un método distinto, cuyo dinamismo y actualización estará sometido a otro proceso racional que, en el

\footnotetext{
${ }^{45}$ El Dictamen 4604/112 de 3 de octubre de 2017 de la Dirección del Trabajo clarifica qué se entiende a estos efectos por riesgo (contingencia o proximidad de un daño, situación potencial no actualizada sea inherente a las faenas o ajenas a ellas), gravedad (de mucha entidad) e inminencia (que amenaza o está para suceder prontamente).
} 
contexto europeo, viene determinado por la capacidad que tienen los adelantos técnicos de proporcionar seguridad.

En efecto, aun cuando el Convenio 155 OIT habla de protección razonable y factible, lo que pudo plantear alguna divergencia interpretativa, en ningún momento las normas internacionales hacen diferencias en la aplicación de sus cláusulas por la actividad económica empresarial; además, el tiempo ha perfilado su naturaleza general, tanto en la letra del derecho positivo más moderno como en la interpretación que se hace del mismo ${ }^{46}$. Por eso, la Directiva Marco europea y sus normas nacionales son entendidas, por el TJCE ${ }^{47}$, en el sentido de que la razonabilidad de la protección no puede estar limitada ni a la capacidad económica ni a la dimensión de la empresa, lo que no excluye que su tamaño se tenga en cuenta en las políticas públicas destinadas a fomentar el cumplimiento normativo, sobre todo para las PYMES, tal y como también recoge el Proyecto de Ley chileno.

Como afirmé, con objeto de resolver este conflicto, las normas europeas consideran que para conseguir la protección eficaz se tendrá en cuenta "la evolución de la técnica" 48 , criterio de razonabilidad con el que habrá de calcularse el alcance de las normas preventivas. La eficacia de la protección se mide evitando el riesgo en el nivel máximo que la técnica permita en cada momento. La actuación preventiva se calcula, por tanto, llegando tan lejos como sea posible técnicamente, más allá, incluso, de lo que sea reglamentario, operando como mecanismo de actuación adicional frente a la obsolescencia normativa típica. Este será el punto de cumplimiento de la obligación empresarial, el "resultado” exigido, aquello que el trabajador podrá exigir, la seguridad que la norma quiere proporcionar.

El ordenamiento preventivo chileno es menos explícito, aunque un ejercicio hermenéutico finalista, sistemático y contextualizado ofrecerá un alcance similar. En este sentido, conviene decir que la paralizada propuesta de cambio legislativo incorpora el elemento técnico como factor de cálculo del alcance de la deuda de seguridad. De esta forma, confiesa de sí misma que su pretensión es la de "proporcionar certeza jurídica del sentido exacto y alcance” del compromiso empresarial sito en el CT y la LAT (Considerando $8^{\circ}$ ). Para ello manifiesta, en su larga Exposición de Motivos, diferentes ideas que hacen entrever la ratio legis de esta futura norma, imprimiendo de un modo más explícito el modo actual de comprender la seguridad laboral. El enfoque se va

46 Los comentarios del Comité de Expertos sobre el C155OIT pueden verse en http://www.ilo.org/dyn/normlex/es/f?p=1000:20010:0::NO:::

${ }^{47}$ La Sentencia 2007/141 de 14 junio del Tribunal de Justicia de las Comunidades Europeas entiende que la Ley del Reino Unido al expresar que la garantía de la salud, seguridad y bienestar se ajustará a la medida que sea razonablemente posible no puede significar una limitación a lo que la empresa esté en condiciones económicas de ofrecer. De todos modos, la adaptación razonable es una categoría jurídica anglosajona que tiene larga data y una interpretación que fue ajena al contexto continental hasta que las Directivas antidiscriminatorias europeas decidieron incorporarla al acervo jurídico comunitario.

${ }^{48}$ Artículo 15 LPRL. 
deslizando a lo largo del texto, en el que la capacidad económica de la empresa no es un valor a tener en cuenta para limitar el derecho del trabajador. En cambio, al perfilar la deuda empresarial, indica que deberá ir adecuando las medidas a los riesgos existentes, teniendo la necesidad de actualizarse, a través de una investigación permanente que preste atención a los nuevos conocimientos técnicos y prácticos ${ }^{49}$.

Desde luego que sería deseable que la propuesta se haga realidad y se formule en términos jurídicamente más seguros, con una mayor certidumbre, diciendo el legislador con claridad que la evolución de la técnica determina el alcance de las medidas de seguridad.

Y no habría ningún obstáculo, en primer lugar, para que esta lógica sea compatible con establecer excepciones, sometiendo algunas medidas a un criterio de razonabilidad en el que participen otros factores de la empresa, como pueden ser los organizativos, productivos o económicos, algo que puede ser muy útil, por ejemplo, cuando se exige la movilidad de un trabajador con especial sensibilidad a un riesgo que pueda generar una enfermedad profesional.

Aunque de igual modo es transcendental no perder la cordura. En ningún caso se pide al empresario una labor de investigación técnica, sino una actualización razonable, utilizando los adelantos que el mercado proporciona. La diligencia de un prudente empresario se traduce, en este punto, en alcanzar la máxima protección ${ }^{50}$ tecnológicamente posible, pauta de conducta que marca "la frontera hasta dónde debe llegar el esfuerzo y el deber empresarial” 51 . Ahora bien, el sentido común impone que el dinamismo de esta conducta sea, en todo caso, mesurado, en un análisis proporcional de los esfuerzos efectuados que incorpore, como variables, tanto el nivel de mejora preventiva que facilita el avance técnico, como el coste de la medida y su impacto sobre el funcionamiento de la empresa.

\section{BIBLIOGRAFÍA}

Baylos Grau, A., La igualdad de las partes en el proceso laboral y la tutela judicial efectiva, Derecho privado y Constitución 4/1994 (Monográfico sobre la tutela judicial efectiva y el proceso de trabajo).

Blat Gimeno, F.R., Relaciones laborales en las empresas ideológicas, MTSS, Madrid 1986.

\footnotetext{
${ }^{49}$ La STJCE de 15 de noviembre de 2001 -Rec. C-49/2000- afirmaba que los riesgos profesionales no están determinados definitivamente, sino que evolucionan de forma constante en función, especialmente, del desarrollo progresivo de las condiciones de trabajo y de las investigaciones científicas en esta materia.

${ }^{50}$ En este sentido, Sala Franco, T., Derecho a la prevención de riesgos laborales, Tirant lo Blanch 2016, p. 105.

${ }^{51}$ González Ortega, S. Y Aparicio Tovar, J., ob. cit. p. 26.
} 
Casas Baamonde, MA Y Valdés Dal-Re, F., "Tutela judicial, competencia de la jurisdicción social y acceso al proceso de trabajo”, Derecho privado y Constitución, 4/1994 (Monográfico sobre la tutela judicial efectiva y el proceso de trabajo).

Cavas Martínez, F., “Supuesta vulneración del derecho a la tutela judicial efectiva: inimputabilidad de los defectos procesales denunciados a acción u omisión del órgano judicial”, Revista Española de Derecho del Trabajo, 66/1994.

Contador Abraham, P. y Rodríguez De Los Ríos, M.F., "Vulneración del derecho a la vida e integridad física y psíquica de los trabajadores. Obligación de seguridad o deber de protección del empleador, no requieren la producción de un daño o accidente, para configurar su incumplimiento", Revista de Derecho Laboral y Seguridad Social, Volumen IV N 6, Santiago de Chile, Thomson Reuters, 2016.

Cruz Villalón, J, “Los derechos constitucionales de los trabajadores extranjeros”, en Las transformaciones del Derecho del Trabajo en el marco de la Constitución Española. Estudios en homenaje al Profesor Miguel Rodríguez-Piñero y Bravo Ferrer, AA.VV., La Ley, Madrid, 2006.

Díez-Picazo Y Ponce De León, L., Notas sobre el derecho a la tutela judicial efectiva, en Estudios de derecho y hacienda, 1/1987.

Echeverri Uruburu, A., "Los derechos sociales como derechos subjetivos fundamentales”, en IUSTA 29/2008, Universidad Santo Tomás, Bogotá.

Fedotov, Saux y Rantanem, "Normas, principios y enfoques de los servicios de salud en el trabajo", en Enciclopedia de salud y seguridad en el trabajo, n 16.

Fernández López, M.F., Libertad ideológica y prestación de servicios, Relaciones Laborales 7/1985.

Figueruelo Burrieza, A., Tutela Judicial efectiva y sistema constitucional de fuentes del derecho, en Los derechos fundamentales y libertades públicas (II) / XIII Jornadas de Estudio, Dirección General del Servicio Jurídico del Estado, Vol. 1/1993.

Gajardo Harboe, M.C., “El deber de seguridad”, Revista Chilena de Derecho del Trabajo y de la Seguridad Social, Volumen 5, N 9, 2014.

Gil-Robles y Gil-Delgado, A., Los nuevos límites de la tutela judicial efectiva, Centro de Estudios Constitucionales, 1996; Martín Valverde, A., Jurisdicción social y tutela judicial efectiva, Derecho privado y Constitución, 4/1994 (Monográfico sobre la tutela judicial efectiva y el proceso de trabajo).

González Labrada, M., Seguridad y salud en el trabajo y responsabilidad contractual del empresario, CEDECS 1996. 
González Ortega, S. y Aparicio Tovar, J., Comentarios a la Ley 31/1995 de prevención de Riesgos Laborales, Trotta, 1996.

Gütiérez-Solaz Calvo, B., El deber de seguridad y salud en el trabajo, CES, 1999.

Igartua Miró, M.T., La Obligación General de Seguridad. Valencia, Tirant lo Blanch 2000

Montt Balmaceda, M., Principios de Derecho Internacional del Trabajo. La OIT, Editorial Jurídica de Chile 1998.

Núñez González, C., “El deber de colaboración del trabajador en la prevención de riesgos laborales”, Revista de Derecho Social 75/2016.

Núñez González, C., Prevención de riesgos laborales en Chile. Alcance y contenido del artículo 184 del Código del Trabajo, Santiago, Chile, Librotecnia, 2ª Ed. 2014.

OIT, Normas de la OIT sobre seguridad y salud en el trabajo. Promover la seguridad y la salud en el medio ambiente de trabajo, OIT Ginebra 2009, pp. 4 y 5. La responsabilidad del empleador surge con motivo del contrato de trabajo, dice la RCSC, Resolución $\mathrm{n}^{\circ}$ 32411, Sala Cuarta, 14 de diciembre de 2006.

Palomeque López, M.C., “Derechos fundamentales y relación laboral”, en El modelo social de la Constitución Española de 1978 (SEMPERE NAVARRO, A., Director), MTAS, Madrid, 2003.

Prieto Sanchís, L., "Los derechos sociales y el principio de igualdad sustancial”, en La universalidad de los derechos sociales: el reto de la inmigración, Tirant lo Blanch / PUV, Valencia 2004.

Rodríguez Piñero, M., "La integración de los derechos fundamentales en el contrato de trabajo”, en El modelo social de la Constitución Española de 1978 (Sempere Navarro, A., Director), MTAS, Madrid, 2003.

Rojas Miño, I. Manual de Derecho del Trabajo, Santiago de Chile, Lexis-Nexis, 2004.

Sáez Lara, C., La tutela judicial efectiva y el proceso laboral, Civitas, 2004.

Sala Franco, T., Derecho a la prevención de riesgos laborales, Tirant lo Blanch 2016.

Salcedo Beltrán, C., El deber de protección empresarial de la seguridad y salud de los trabajadores, Tirant lo Blanch 2000.

Terradillos Ormaetxea, E., El poder disciplinario empresarial. Principios y garantías, Tirant lo Blanch, Valencia 2004.

Valdeolivas García, Y., "Las fuentes del deber de seguridad: obligación contractual y desarrollo normativo”, en AA.VV., Cuadernos de Derecho Judicial. Ley de Prevención 
de Riesgos Laborales. Últimas reformas y análisis de la normativa específica en la materia. Madrid (CGPJ), 2006.

Válticos, Derecho internacional del trabajo, Tecnos 1977. 